\title{
Clarifying the Baroclinic Contribution to the Great Plains Low-Level Jet Frequency Maximum
}

\author{
JOSHUA G. GEBAUER \\ School of Meteorology, University of Oklahoma, Norman, Oklahoma
}

ALAN SHAPIRO

School of Meteorology, and Center for Analysis and Prediction of Storms, University of Oklahoma, Norman, Oklahoma

(Manuscript received 28 January 2019, in final form 3 July 2019)

\begin{abstract}
The frequency and intensity of the Great Plains nocturnal low-level jet (LLJ) are enhanced by baroclinicity over the sloped terrain of the region. A classical description of baroclinic-induced diurnal wind oscillations over the Great Plains considers differential heating of the slope with respect to air at the same elevation far removed from the slope, but with buoyancy constant along the slope (Holton mechanism). Baroclinicity can also occur due to differential heating of the slope itself, which creates a gradient in buoyancy along the slope. The relative prevalence of the two types of baroclinicity in this region has received scant attention in the literature. The present study uses 19 years of data from the Oklahoma Mesonet to evaluate the characteristics of along-slope buoyancy gradients over the region. A mean negative afternoon along-slope buoyancy gradient (east-west gradient) is found over Oklahoma. The sign of this afternoon buoyancy gradient is favorable for LLJ formation, as it results in the strongest southerly geostrophic wind near the ground around sunset, which is conducive to nocturnal jet formation via the inertial oscillation mechanism. The negative afternoon buoyancy gradient is at least partially created by an east-west gradient in diurnal heating and is stronger and more consistent in the summer months, which is when LLJs are most frequent. The contribution of the alongslope buoyancy gradient to the low-level geostrophic wind was found to be as important as the contribution of the Holton mechanism. Overall, these results indicate that along-slope buoyancy gradients should be accounted for in studies of LLJ dynamics over the Great Plains.
\end{abstract}

\section{Introduction}

Climatological studies have revealed a well-defined maximum in the frequency and intensity of southerly low-level wind maxima over the southern Great Plains (Bonner 1968; Walters et al. 2008; Rife et al. 2010; Doubler et al. 2015). This phenomenon has been named the Great Plains low-level jet (LLJ). The LLJ is primarily a nocturnal feature and typically occurs below $1000 \mathrm{~m}$, with a peak wind often just a few hundreds of meters above the ground. The LLJ plays an important role in the weather and climate of the Great Plains as it transports moisture into the region (Rasmusson 1967; Higgins et al. 1997) and can promote or initiate convection (Pitchford and London 1962; Maddox 1983; Astling et al. 1985; Gebauer et al. 2018). The LLJ is often associated with 3-5 day heavy

Corresponding author: Joshua Gebauer, joshua.gebauer@ou.edu rainfall corridors that significantly contribute to the region's total yearly precipitation (Carbone et al. 2002; Trier et al. 2006; Tuttle and Davis 2006; Trier et al. 2014). The mechanism(s) by which LLJ-associated convergence arises is still an active area of research (e.g., Shapiro et al. 2018).

Although progress has been made in elucidating the cause of the Great Plains LLJ, there are still questions on its exact forcing. The LLJ is primarily the result of an inertial oscillation arising from a force imbalance that develops when thermally generated turbulence decays at sunset (Blackadar 1957; Parish et al. 1988; Zhong et al. 1996). This inertial oscillation produces a clockwise turning of the ageostrophic wind vector, with peak supergeostrophic wind speeds occurring when the ageostrophic wind aligns with the geostrophic wind, often in the early morning hours. Since inertial oscillations can produce LLJs at any location with a nonnegligible Coriolis force and synoptic-scale pressure 
gradient force, one would not expect such a mechanism to produce a well-defined spatial maximum in LLJ frequency. Therefore, there must be an additional mechanism(s) over the Great Plains that either enhances the inertial oscillation or creates an environment that is more favorable for the inertial oscillation to produce LLJs. Several studies have suggested that some type of thermal forcing over the slightly sloped terrain of the Great Plains is a likely cause of the frequent LLJs in that region (e.g., Holton 1967; Bonner and Paegle 1970; Parish and Oolman 2010; Du and Rotunno 2014; Shapiro et al. 2016; Parish 2017). However, there are multiple ways heating of the sloped terrain can enhance LLJs. Holton (1967) showed that a uniform diurnal heating of a planar slope creates a diurnal oscillation of the southerly wind, even with temporally constant mixing coefficients. Although this oscillation is out of phase with the observed wind oscillation and is much weaker than the wind maxima typically observed, Bonner and Paegle (1970), Du and Rotunno (2014), and Shapiro et al. (2016) analytically showed that the Holton mechanism can act synergistically with the Blackadar mechanism to yield stronger nocturnal LLJs. Therefore, the Holton (1967) mechanism could potentially be a major contributor to the Great Plains LLJ maximum. On the other hand, Parish (2017) argues that this diurnal heating effect only has a small impact on the LLJ. According to Parish (2017), the Great Plains LLJ maximum is due to seasonal mean heating of the sloped terrain. Seasonal heating of the slope creates a seasonal oscillation of the southerly geostrophic wind over the Great Plains with the geostrophic wind being strongest in the summer months. The strong mean low-level geostrophic southerly flow during the summer combined with the Blackadar mechanism results in more frequent LLJs. As Parish (2017) notes, the forcing of this seasonal oscillation is similar to the Holton diurnal oscillation, but differs in the time scale.

While diurnal and mean seasonal heating both likely affect the LLJ, the Holton (1967) and Parish (2017) studies do not address a second potential baroclinic factor: uneven heating of the slope. A heated sloping surface such as the surface of the Great Plains can generate across-slope vorticity (i.e., northward pointing in the case of the Great Plains) through two mechanisms. In one mechanism, a horizontal buoyancy gradient (i.e., between an air parcel adjacent to the slope and air at the same elevation as that parcel but remote from the slope) is created by a uniformly heated slope (the Holton mechanism). The second mechanism is the generation of northward pointing vorticity by an along-slope buoyancy gradient (uneven heating of the slope with potential temperature increasing toward the west). This mechanism would operate even in the absence of a slope, that is, over a horizontal surface. This second source of baroclinicity can significantly affect the low-level wind profile. Bonner and Paegle (1970) implicitly included this effect in their calculation of the diurnal change in thermal wind for their analytical model, but their subsequent discussion focused on the Holton mechanism (with the caveat that uneven heating of the slope may also be important).

Parish (2017) uses temperature gradients on isobaric surfaces to quantify the effect of mean seasonal heating over the Great Plains. However, because constant pressure surfaces pass through the atmospheric boundary layer obliquely (before impinging on the slope) it is difficult for an isobaric analysis to distinguish between baroclinicity caused by the uniform heating of a surface with a nonzero slope angle (Holton or Parish theory), and baroclinicity caused by along-slope variations in heating. To separate these effects, one should work in a slopefollowing coordinate system.

Consider a Cartesian coordinate system in which the unit vector $\mathbf{i}$ points down the slope (which is eastward for the case of the Great Plains), the unit vector $\mathbf{j}$ points across the slope (i.e., northward), and the slope normal unit vector $\mathbf{k}$ is offset from the true vertical direction by the slope angle $\alpha$. We denote by $x, y$, and $z$, the coordinates aligned with $\mathbf{i}, \mathbf{j}$, and $\mathbf{k}$, respectively [see Fig. 1 in Shapiro et al. (2016)]. Using this coordinate system and applying the Boussinesq approximation, the equation for the north-south component of geostrophic wind becomes

$$
V_{g}=\frac{1}{f}\left(\frac{\partial \Pi}{\partial x}+b \sin \alpha\right)
$$

where $f$ is the Coriolis parameter. Perturbation pressure is defined as $\Pi=\left[p-P\left(z^{*}\right)\right] / \rho_{0}$, where $p$ is pressure, $P\left(z^{*}\right)$ is a hydrostatic reference pressure, a function of the true vertical coordinate $z^{*}$, and $\rho_{0}$ is a constant density. Buoyancy is defined as $b=$ $g\left[\theta_{v}-\theta_{f}\left(z^{*}\right)\right] / \theta_{0}$, where $g$ is the acceleration due to gravity, $\theta_{v}$ is virtual potential temperature, $\theta_{f}\left(z^{*}\right)$ is the free-atmosphere (also known as reference) potential temperature, a function of the true vertical coordinate $z^{*}$, and $\theta_{0}$ is a constant value of potential temperature, typically taken to be $300 \mathrm{~K}$. Both the Holton and Parish theories account for the buoyancy term in (1), in which the buoyancy contribution toward the meridional geostrophic wind speed is weighted by the sine of the slope angle. It is important to note, 
however, that the pressure gradient term in (1) is also related to buoyancy, specifically to the buoyancy gradients along the slope. This can be shown using the Boussinesq quasi-hydrostatic equation (Mahrt 1982; Shapiro et al. 2016):

$$
\frac{\partial \Pi}{\partial z}=b \cos \alpha .
$$

Taking the along-slope derivative $(\partial / \partial x)$ of $(2)$ and rearranging the order of differentiation in the pressure gradient term yields

$$
\frac{\partial}{\partial z}\left(\frac{\partial \Pi}{\partial x}\right)=\frac{\partial b}{\partial x} \cos \alpha
$$

Equation (3) shows that when an along-slope buoyancy gradient is present, the along-slope pressure gradient must change with height (i.e., a thermal wind exists). LLJ theories that assume constant buoyancy along a slope (i.e., uniform heating), as in the Holton (1967) theory, do not account for this effect.

Gebauer et al. (2018) showed three examples of Great Plains LLJs that developed in the presence of a negative along-slope buoyancy gradient. These buoyancy gradients increased in magnitude in phase with the diurnal heating cycle. Bonner and Paegle (1970) documented a similar result over an eight-day study period over the southern Great Plains (see their Fig. 9), but instead of using buoyancy as the thermodynamic variable, they used the altimeter correction system developed by Bellamy (1945). For more information on how the frameworks are related see appendix. According to (3) and (1), a negative along-slope buoyancy gradient is associated with a decrease in the southerly geostrophic wind with height. Therefore, a negative buoyancy gradient creates a favorable geostrophic wind profile for LLJ development via the Blackadar mechanism; having the strongest southerly geostrophic winds near the surface not only increases the strength of the LLJ, but also helps create the necessary shear for the wind maximum to be classified as an LLJ. If significant negative buoyancy gradients associated with nonuniform heating of the underlying surface are common over the Great Plains, then they might be a major contributor to the Great Plains LLJ maximum. This study attempts to identify if along-slope buoyancy gradients of sufficient magnitude to affect LLJs are common over the region, and examines the role of the diurnal cycle in their creation.

\section{Methods}

A 19-yr record of observations from the Oklahoma Mesonet (Brock et al. 1995; McPherson et al. 2007) from
January 1999 to December 2017 is used for this study. The Oklahoma Mesonet records basic meteorological surface variables at 120 quasi-regularly spaced sites in Oklahoma ( $\sim 1$ site per county). Because of its high density of observation locations, the mesonet provides an excellent dataset to analyze buoyancy gradients in this region. Since buoyancy is not directly measured, the virtual potential temperature gradient is used as a proxy for the buoyancy gradient. Virtual potential temperature at each mesonet location was calculated from the observed $2 \mathrm{~m}$ temperature, $2 \mathrm{~m}$ relative humidity, and surface pressure. In the special case where the buoyancy is uniform along the slope $(d b / d x=0)$ and one assumes that the free atmosphere buoyancy frequency $N\left[N^{2}=\left(g / \theta_{0}\right) d \theta_{f} / d z^{*}\right]$ does not vary spatially, then $\partial \theta_{v} / \partial x=\partial \theta_{f} / \partial x=\left(d \theta_{f} / d z^{*}\right)\left(\partial z^{*} / \partial x\right)$ and we obtain

$$
\frac{\partial \theta_{v}}{\partial x}=-\frac{\theta_{0}}{g} N^{2} \sin \alpha
$$

Observations indicate that within the free atmosphere (of the lower troposphere) $N$ is remarkably uniform (Tsuda et al. 1991; Revathy et al. 1996). We take $N$ to be the typical value of $0.01 \mathrm{~s}^{-1}$. Accordingly, if an observed virtual potential temperature gradient deviates from (4) then it suggests that an along-slope buoyancy gradient is present.

The gradient of the maximum surface virtual potential temperature can reasonably represent the gradient of the maximum virtual potential temperature throughout the depth of the mixed layer during the daytime, and the residual layer during the overnight hours. Additionally, the strength of the overnight LLJ is directly related to the geostrophic wind maximum in the late afternoon, even though the geostrophic wind maximum is out of phase with the inertial oscillation (Bonner and Paegle 1970; Shapiro et al. 2016). Therefore, even if the gradients of surface virtual potential temperature weaken during the overnight hours, the LLJ is still affected by the stronger daytime gradient. For these reasons, compositing of the gradient of maximum virtual potential temperature across the mesonet was done for afternoons prior to LLJ nights $(C=2730)$ and afternoons prior to non-LLJ nights $(C=4203)$. LLJ nights were identified from the 1200 UTC radiosonde wind profiles at the OUN sounding site in Norman, Oklahoma, using the jet profile altitude requirements from Bonner (1968) and the jet intensity criteria from Walters and Winkler (2001). Specifically, a night was classified as an LLJ night if the low-level wind profile met the following criteria: 1 ) a local wind speed maximum occurred within $1.5 \mathrm{~km}$ of the ground, 2) this maximum 
was greater than $8 \mathrm{~m} \mathrm{~s}^{-1}, 3$ ) at least a $4 \mathrm{~m} \mathrm{~s}^{-1}$ decrease in wind speed occurred above and below the maximum, 4) the previous three conditions were within $3 \mathrm{~km}$ of the surface, and 5) the wind direction of the wind speed maximum was between $120^{\circ}$ and $240^{\circ}$. A non-LLJ night was a night when the wind profile did not meet all of the LLJ criteria.

As a first step in the compositing procedure, the maximum virtual potential temperature on a given day was found at each site and the spatial mean of those maxima across the mesonet on that day was removed from each maxima to obtain spatial anomalies of the maximum virtual potential temperature. Mathematically,

$$
\theta_{v_{\max _{d}}^{s^{\prime}}}^{\prime^{\prime}}=\theta_{v_{\max _{d}}}-\overline{\theta_{v_{\max _{d}}}},
$$

where $d$ is an index representing a day in the composite, $\theta_{v_{\max _{d}}}$ is the daily maximum virtual potential temperature, $\overline{\theta_{v_{\max _{d}}}}$ is the spatial mean of the daily maximum virtual potential temperature across the mesonet, and $\theta_{v_{\max _{d}}^{s^{\prime}}}$ is the spatial anomaly of the daily maximum virtual potential temperature. The composites were then created from these spatial anomalies using the following equation:

$$
\hat{\theta}_{v_{\max }}^{s^{\prime}}=\frac{1}{C} \sum_{d=1}^{C} \theta_{v_{\max _{d}}^{s^{\prime}}}^{s^{\prime}}
$$

Here, $C$ is the number of days in the composite and the quantity $\hat{\theta}_{v_{\max }^{\prime}}^{s^{\prime}}$ is the composite mean of the spatial anomalies of the maximum virtual potential temperature. Composites were computed separately for afternoons prior to LLJ nights and afternoons prior to non-LLJ nights.

Composites of the diurnal cycle of virtual potential temperature were created in a manner similar to the maximum virtual potential temperature composites, with compositing again performed separately for the categories of afternoons prior to LLJ nights and afternoons prior to non-LLJ nights. The site specific daily mean was removed from the daily virtual potential temperature time series at each mesonet location to obtain daily temporal anomalies of virtual potential temperature. Mathematically,

$$
\theta_{v_{d}}^{t^{\prime}} c(t)=\theta_{v_{d}}(t)-{\overline{\theta_{v_{d}}}}^{t},
$$

where $\theta_{v_{d}}(t)$ is the daily virtual potential temperature that is a function of time, ${\overline{\theta_{v_{d}}}}^{t}$ is the temporal mean of the daily virtual potential temperature, and $\theta_{v_{d}}^{t^{\prime}}(t)$ is the temporal anomalies of daily virtual potential temperature. The compositing was then conducted at each site on the temporal anomalies of the daily virtual potential temperature using

$$
\hat{\theta}_{v}^{t^{\prime}}(t)=\frac{1}{C} \sum_{d=1}^{C} \theta_{v_{d}}^{t^{\prime}}(t)
$$

where $\hat{\theta}_{v}^{t^{\prime}}(t)$ is the composite mean virtual potential temperature over the diurnal cycle. The average peakto-peak amplitude of the diurnal cycle at each location, $\hat{\theta}_{v}^{\mathrm{AMP}}$, was calculated as the difference between the maximum and minimum of the composited diurnal cycle of virtual potential temperature:

$$
\hat{\theta}_{v}^{\mathrm{AMP}}=\max \left[\hat{\theta}_{v}^{t^{\prime}}(t)\right]-\min \left[\hat{\theta}_{v}^{t^{\prime}}(t)\right] .
$$

Additionally, seasonal composites of maximum virtual potential, diurnal cycle of virtual potential temperature, and soil moisture were created and analyzed to evaluate the role of soil moisture in creating buoyancy gradients. These composites were also used to determine the seasonal changes in the gradients. The soil moisture variable used is $5 \mathrm{~cm}$ fractional water index (Schneider et al. 2003):

$$
\mathrm{FWI}=\frac{\Delta T_{d}-\Delta T_{\mathrm{ref}}}{\Delta T_{d}-\Delta T_{w}}
$$

where $\Delta T_{d}=3.96^{\circ} \mathrm{C}$ is the reference response when the soil moisture sensor is dry, $\Delta T_{w}=1.38^{\circ} \mathrm{C}$ is the reference response when the sensor is immersed, and $\Delta T_{\text {ref }}$ is the reference temperature difference measured by the sensor. This index was calculated from the $5 \mathrm{~cm} \Delta T_{\text {ref }}$ data provided by the Oklahoma Mesonet.

Finally, the covariance between the spatial anomalies of maximum potential temperature for each afternoon and the temporal mean of the spatial anomalies of maximum potential temperature was calculated. This is defined as

$$
\operatorname{cov}_{d}=\frac{1}{M-1} \sum_{m=1}^{M}\left(\theta_{v_{\max _{d}}^{s^{\prime}}}\right)_{m}\left(\frac{1}{D} \sum_{d=1}^{D} \theta_{v_{\max _{d}}^{s^{\prime}}}^{s_{m}}\right)_{m},
$$

where $D$ is the total number of days in the dataset, $M$ is the number of mesonet stations, and $m$ is an index representing each mesonet station. Since each day is being covaried against the same temporal mean of the spatial anomalies, the values of the covariance can be compared against one another to obtain an idea of the relative strength of the virtual potential temperature gradient on each day. Covariance values themselves are not particularly meaningful, so it is convenient to standardize the covariance time series so the values 


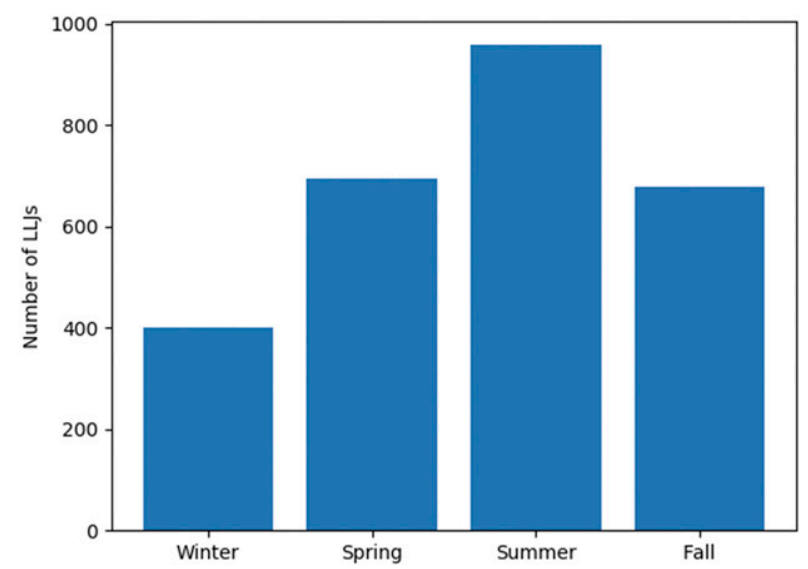

FIG. 1. The number of southerly LLJs at OUN in meteorological winter (December, January, February), spring (March, April, May), summer (June, July, August), and fall (September, October, November) from January 1999 to December 2017.

are standard deviations away from the mean covariance. This creates an index that represents the strength of the virtual potential temperature gradient on each day. The average index and the standard deviation of the index were found for each month, allowing the seasonality of the gradients to be assessed.

\section{Results}

Southerly LLJs were found to occur most frequently in the summer months and least frequently in the winter (Fig. 1) This is in agreement with other studies of southerly LLJ frequency over the Great Plains (Whiteman et al. 1997; Song et al. 2005). For both afternoons prior to LLJ nights and afternoons prior to non-LLJ nights, the composite mean shows a negative buoyancy gradient across Oklahoma (Figs. 2a,b). The significance of the composites was tested against the virtual potential temperature gradient expected if no along-slope buoyancy gradient was present (Fig. 2c). The virtual potential temperature field for this special case was produced by integrating (4) with respect to $x$, which yields

$$
\theta_{v}=\frac{\theta_{0}}{g} N^{2} z^{*}+\text { const. }
$$

The value of the constant is irrelevant for our purposes since the spatial mean is removed from the values. Using a two-sided $t$ test, the composites at most locations were found to be statistically significant against the constant buoyancy virtual potential temperature gradient at the $99 \%$ confidence level. The only locations that were not significant were in the central part of Oklahoma, where the spatial anomalies were near (a)

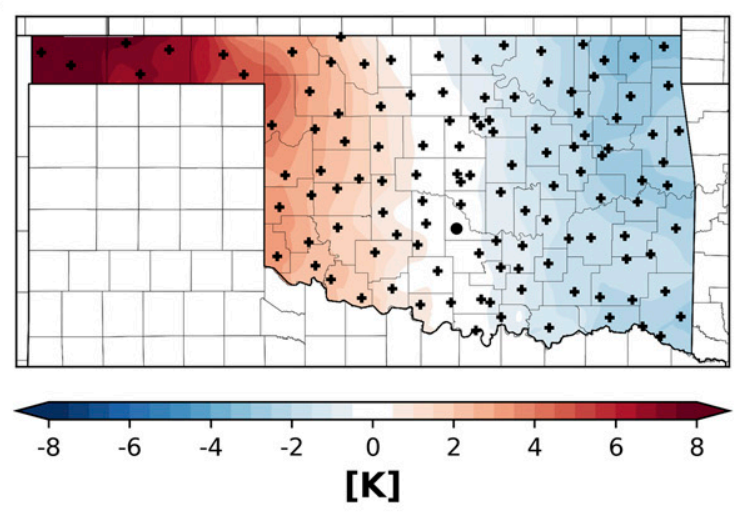

(b)

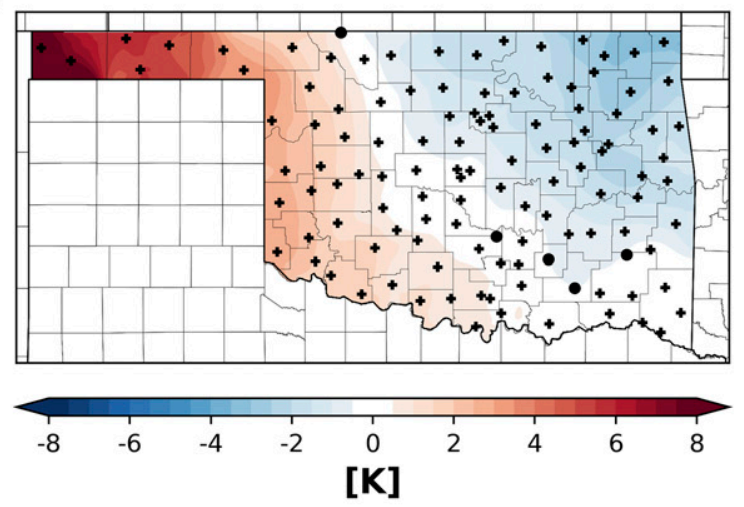

(c)

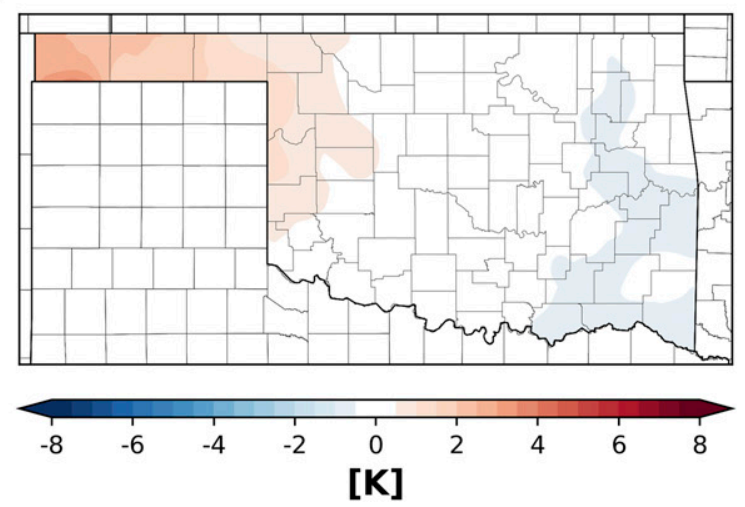

FIG. 2. (a) Composite of spatial anomalies of maximum virtual potential temperature $\left(\hat{\theta}_{v_{\max }}^{s^{\prime}}\right)$ for afternoons prior to LLJ nights. (b) As in (a), but for afternoons prior to non-LLJ nights. (c) The spatial anomalies of maximum virtual potential temperature in the absence of an along-slope buoyancy gradient. In (a),(b) the crosses represent mesonet sites where the composites were statistically significant at the $99 \%$ confidence level against the no-buoyancygradient realization. Circles indicate sites where results were not statistically significant.

zero and, therefore, were close to the values expected for the constant buoyancy realizations.

The average along-slope virtual potential temperature gradient for afternoons prior to LLJ nights was 
(a)

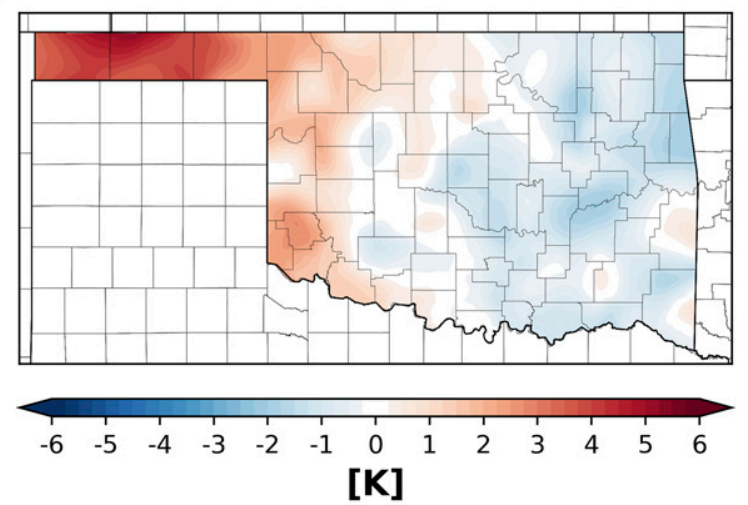

(b)

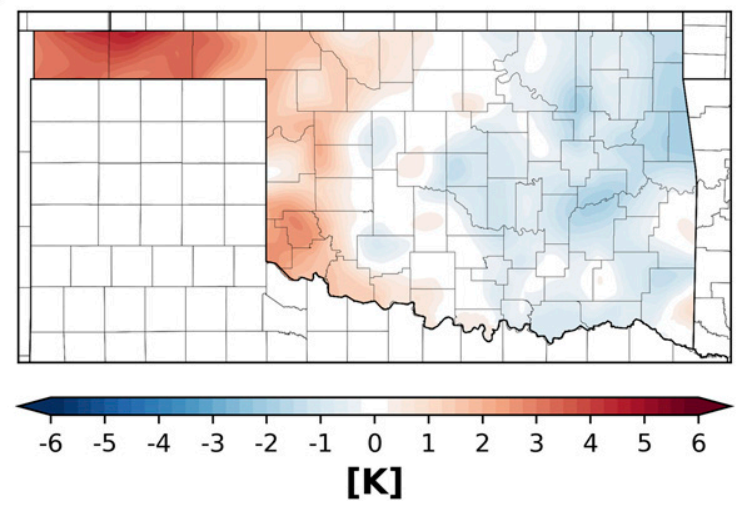

FIG. 3. (a) Composite of the spatial anomalies of the virtual potential temperature diurnal cycle amplitude $\left(\hat{\theta}_{v}^{\mathrm{AMP}}\right)$ for afternoons prior to LLJ nights. (b) As in (a), but for afternoons prior to non-LLJ nights.

found to be $-1.30 \times 10^{-5} \mathrm{~K} \mathrm{~m}^{-1}$ while the average alongslope virtual potential temperature gradient for afternoons prior to non-LLJ nights was $-9.7 \times 10^{-6} \mathrm{~K} \mathrm{~m}^{-1}$. The buoyancy gradient can be estimated by

$$
\frac{\partial b}{\partial x}=\frac{g}{\theta_{0}} \frac{\partial \theta_{v}}{\partial x}+N^{2} \sin \alpha
$$

Assuming an average slope angle of 0.1 , this yields a buoyancy gradient of $-2.501 \times 10^{-7} \mathrm{~s}^{-2}$ for afternoons prior to LLJ nights and $-1.423 \times 10^{-7} \mathrm{~s}^{-2}$ for afternoons prior to non-LLJ nights. The $y$ component of the thermal wind associated with these gradients can be calculated from

$$
\frac{\partial V_{g}}{\partial z}=\frac{1}{f} \frac{\partial b}{\partial x} \cos \alpha
$$

The meridional thermal wind was $-2.501 \mathrm{~m} \mathrm{~s}^{-1} \mathrm{~km}^{-1}$ for afternoons prior to LLJ nights and $-1.424 \mathrm{~m} \mathrm{~s}^{-1} \mathrm{~km}^{-1}$ for afternoons prior to non-LLJ nights. These results indicate that along-slope buoyancy gradients tend to be stronger (a)

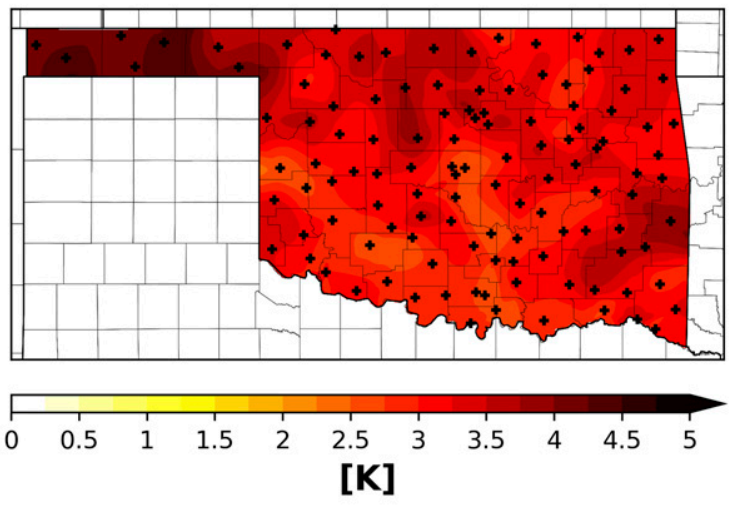

(b)
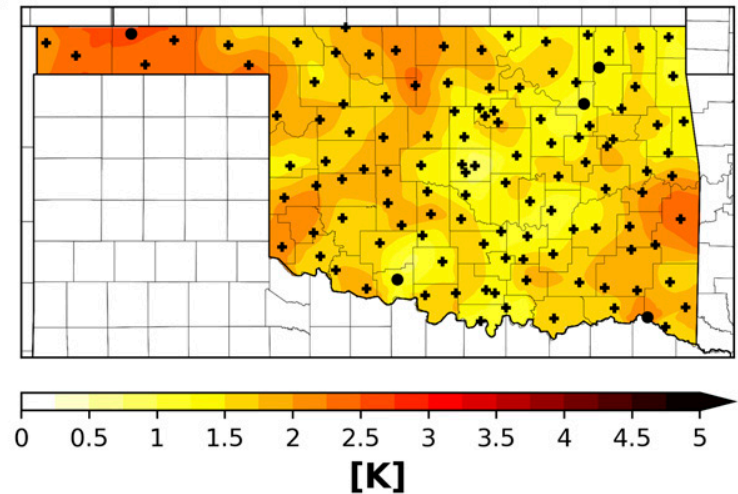

FIG. 4. Composite difference of virtual potential temperature diurnal cycle amplitude (K) between afternoons prior to LLJ nights and afternoons prior to non-LLJ nights for (a) all months in the composite and (b) just the summer months. Crosses indicate sites where the difference was statistically significant at the $99 \%$ confidence level. Circles indicate sites where results were not statistically significant.

on afternoons prior to LLJ. This increases the vertical shear in the southerly geostrophic wind resulting in the southerly geostrophic wind being strongest at low levels, which is a favorable geostrophic wind profile for southerly LLJ formation via the inertial oscillation. The composites also suggest that along-slope buoyancy gradients are a common occurrence over Oklahoma and, therefore, their effects on the LLJ should not be ignored.

The virtual potential temperature diurnal cycle composites indicate that an east-west along-slope gradient in the virtual potential temperature diurnal cycle amplitude contributes toward the negative buoyancy gradients in the afternoon (Fig. 3). The gradient in the diurnal temperature cycle amplitude is not significantly different for afternoons prior to LLJ nights and afternoons prior to non-LLJ nights. However, there is a significant difference in the amplitude of the diurnal temperature cycle between these composites (Fig. 4a). 

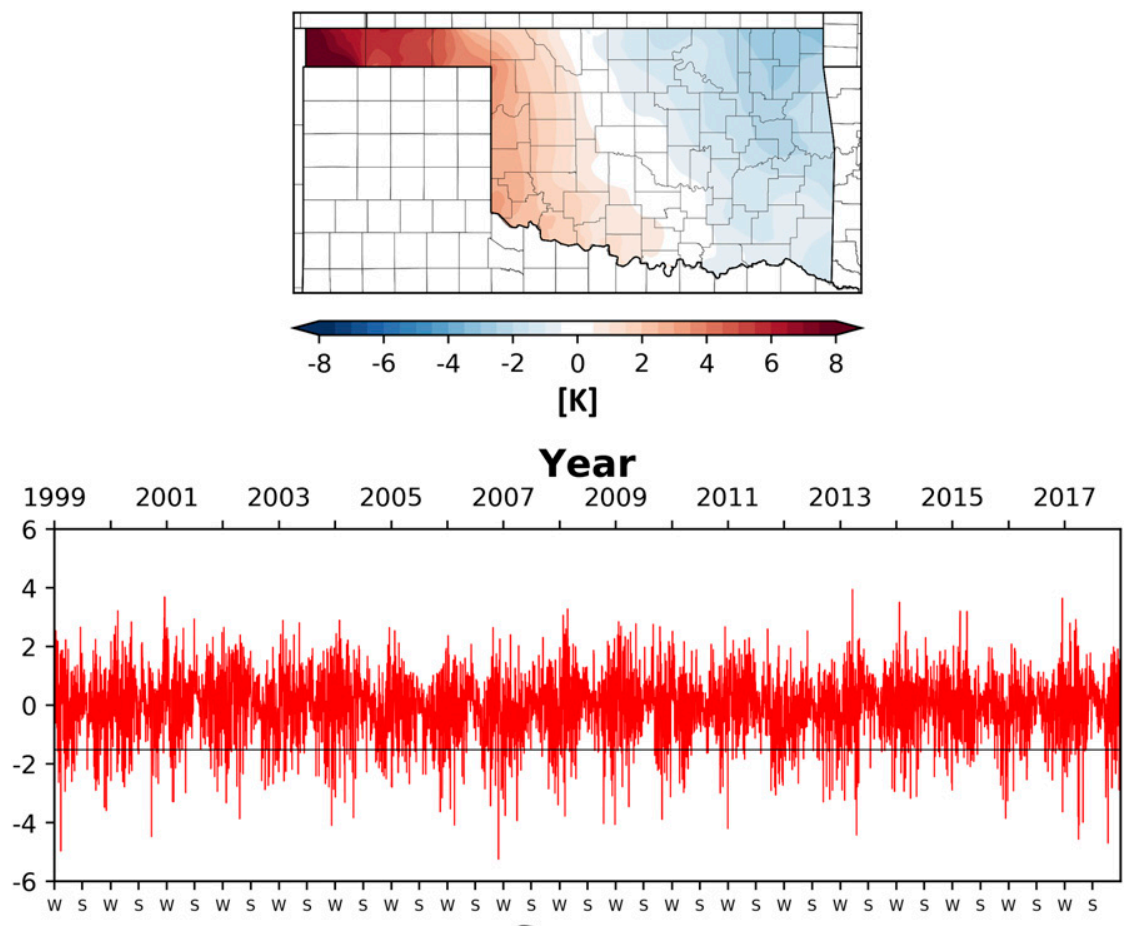

Season

FIG. 5. (top) The average spatial anomalies of maximum virtual potential temperature anomalies from the Oklahoma Mesonet from January 1999 to December 2017. (bottom) The standardized covariance time series between the daily spatial maximum temperature anomalies and the average spatial maximum potential temperature anomalies from the Oklahoma Mesonet. The black line represents the standardized covariance value that represents a covariance of 0 . The ' $S$ ' and ' $W$ ' represents the summer and winter, respectively.

A larger diurnal cycle occurs at all mesonet locations on afternoons prior to LLJ nights, and this difference was found to be statistically significant at the $99 \%$ confidence level at all mesonet locations. This difference is likely due to the seasonality of the LLJ. The average peak-to-peak amplitude for the diurnal temperature cycle across the mesonet for meteorological winter, spring, summer, and fall was 9.87, 10.56, 11.29, and $11.31 \mathrm{~K}$, respectively. LLJs are most frequent in the summer and least frequent in the winter, so the prior to LLJ night composites has more summer days included $(35.1 \%$ of the composite compared to $14.7 \%$ in winter, $25.4 \%$ in spring, and $24.8 \%$ in fall) while the prior to non-LLJ nights has more winter days included $(31.1 \%$ of the composite compared to $18.8 \%$ in summer, $25.1 \%$ in spring, and $25.0 \%$ in fall). This causes the amplitude of the diurnal cycle to be larger in prior-to-LLJ-night composites. However, there are also potential physical reasons for this difference. The strength of the Holton mechanism is directly proportional to the diurnal increase in temperature; therefore, the difference in the composites could be due to the Holton mechanism, since LLJs would be stronger when the preceding day has a large diurnal increase in temperature. The composites of afternoons prior to LLJ nights and afternoons prior to non-LLJ nights for just the summer months highlight this effect, as afternoons prior to LLJ nights during the summer have a larger diurnal cycle than afternoons prior to non-LLJ nights during the summer (Fig. 4b). This difference was found to be significant at the $99 \%$ confidence level at all but 5 sites.

The contribution from the Holton mechanism to the geostrophic wind at the surface can be estimated from the virtual potential temperature diurnal cycle amplitude. The change in virtual potential temperature with time is related to the change in buoyancy with time as

$$
\frac{\partial b}{\partial t}=\frac{g}{\theta_{0}} \frac{\partial \theta_{v}}{\partial t}
$$

assuming that the free atmosphere potential temperature does not change in time. Equation (15) can be discretized to yield

$$
\Delta b=\frac{g}{\theta_{0}} \Delta \theta_{v}
$$


where $\Delta b$ is the difference in buoyancy and $\Delta \theta_{v}$ is the corresponding difference in virtual potential temperature. The average max-min amplitude of the diurnal cycle of virtual potential temperature across the mesonet on afternoons prior to LLJs was $12.025 \mathrm{~K}$. Using (16), the change in buoyancy over the full diurnal cycle is $0.392 \mathrm{~m} \mathrm{~s}^{-2}$. This value is very close to the $0.4 \mathrm{~m} \mathrm{~s}^{-2}$ diurnal range assumed by Shapiro et al. (2016). Assuming that the magnitudes of the daily maximum and minimum of buoyancy are the same, the buoyancy maximum for afternoons prior to LLJ nights is $0.196 \mathrm{~m} \mathrm{~s}^{-2}$. The change in the meridional geostrophic wind in time due to the change in buoyancy with time can be expressed as

$$
\frac{\partial V_{g}}{\partial t}=\frac{1}{f} \frac{\partial b}{\partial t} \sin \alpha
$$

Discretizing this expression yields,

$$
\Delta V_{g}=\frac{1}{f} \Delta b \sin \alpha,
$$

where $\Delta V_{g}$ is the change in the meridional geostrophic wind. Assuming an average slope angle of $0.1^{\circ}$, the Holton mechanism contribution of the surface geostrophic wind is $3.42 \mathrm{~m} \mathrm{~s}^{-1}$. This can be compared to the contribution of the along-slope buoyancy gradients to the surface geostrophic wind. If we assume a well-mixed boundary layer that is $1.5 \mathrm{~km}$ deep, a typical value over Oklahoma (Schmid and Niyogi 2012), the contribution to the geostrophic wind at the surface due to the buoyancy gradient is $3.75 \mathrm{~m} \mathrm{~s}^{-1}$. Thus, the Holton mechanism and buoyancy gradients have a similar contribution to the meridional geostrophic wind.

The standardized covariance time series between the daily spatial virtual potential temperature anomaly and the mean (Fig. 5) shows that there is a clear seasonal cycle in the variability of the along-slope buoyancy gradient pattern over Oklahoma. When considering the time series of the standardized covariances it is important to remember that the values are standard deviations away from the average covariance. Since the mean buoyancy gradient is negative and the mean covariance was 4.089 , a standardized covariance of zero indicates that a negative virtual potential temperature gradient was present. A positive virtual potential temperature gradient has a standardized covariance that is less than -1.518 . During the winter, spring, and fall, the standardized covariance is more variable, with negative standardized covariances (weak negative or positive buoyancy gradients) occurring (a)

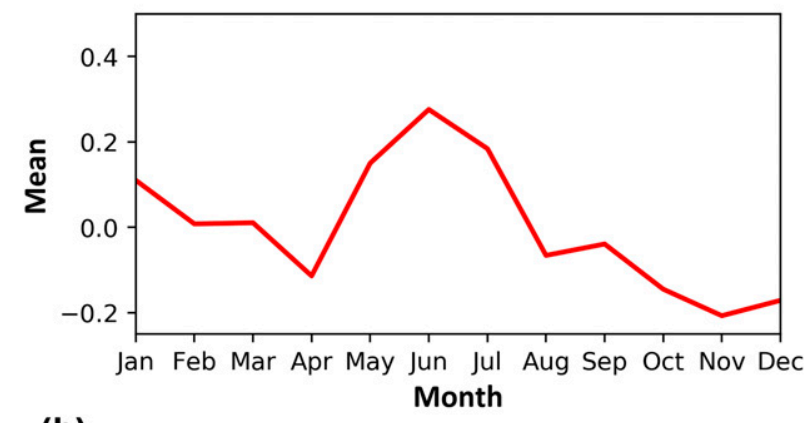

(b)

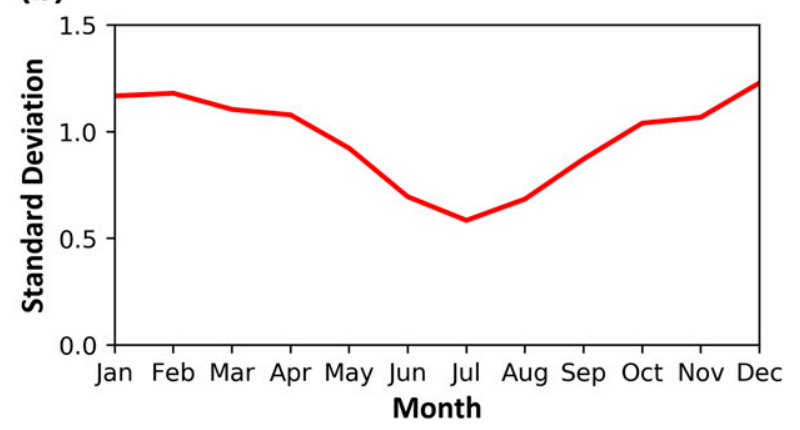

FIG. 6. The (a) mean and (b) standard deviation of the daily standardized covariances between the daily spatial potential temperature anomalies and the average spatial potential temperature anomalies across the Oklahoma Mesonet.

frequently. However, in the summer there is less variability in the buoyancy gradient strength and the standardized covariance is near zero or slightly positive. The monthly average and standard deviation of the standardized covariances shows this more clearly (Fig. 6). The average standardized covariance is at a maximum in June, and the standard deviation of the standardized covariances is at a minimum in July. This indicates that negative along-slope buoyancy gradients are on average stronger and more consistent during the summer months, which is also when LLJs are most frequent. The persistence of this negative buoyancy gradient pattern during the summer months likely contributes to the increase in LLJ frequency during this time.

\section{Potential causes of the buoyancy gradients}

Although the causes of the buoyancy gradients documented in this study are beyond the scope of this work, we now speculate on some relevant mechanisms that might be explored in future studies. The cause of the climatological east-west buoyancy gradient over the Great Plains is difficult to identify. As discussed in the previous section, there is an east-west gradient in the diurnal cycle amplitude that contributes to a 
(a)

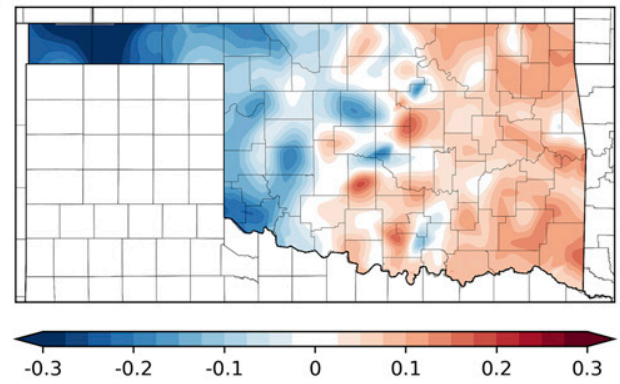

(c)

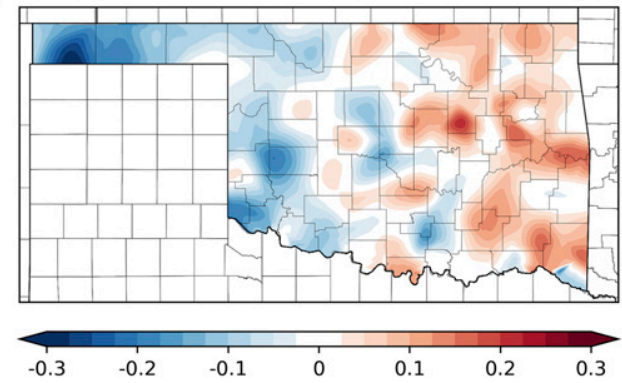

(b)

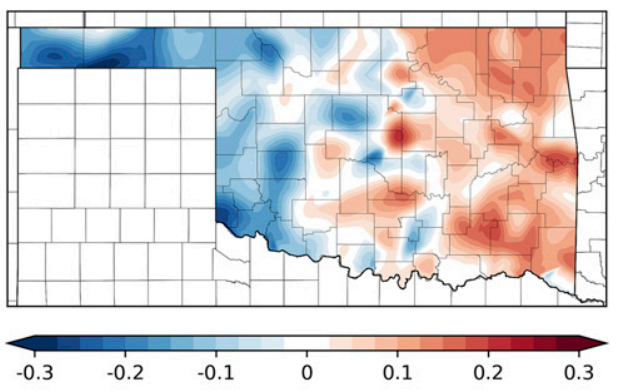

(d)

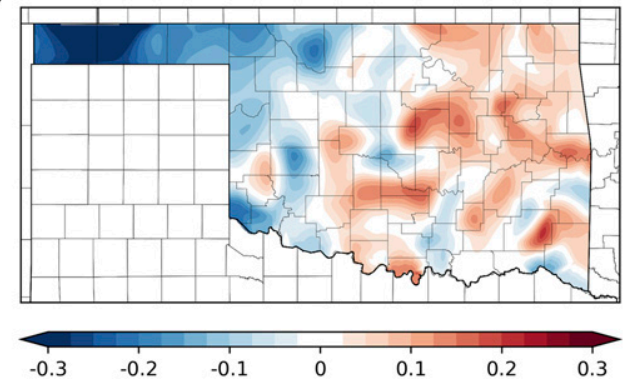

FIG. 7. Composite spatial anomalies of fractional water index for meteorological (a) winter, (b) spring, (c) summer, and (d) fall.

negative along-slope buoyancy gradient in the late afternoon. The gradient in diurnal cycle amplitude is closely aligned with the climatological soil moisture gradient in this region (Fig. 7). Prior studies have found that this east-west soil moisture gradient results in stronger LLJs, primarily due to the horizontal differences in the sensible and latent heat fluxes during the daytime, which result in a stronger temperature gradient over the region (Fast and McCorcle 1990). However, the relationship between the gradient in the diurnal cycle amplitude and soil moisture gradients involves complicated but poorly understood land-atmosphere feedbacks. For instance, horizontal variations in wind speed and static stability above the boundary layer affect the surface fluxes and growth of the boundary layer, respectively, which can also affect the diurnal cycle amplitude and resulting buoyancy gradients. Additionally, soil moisture and the gradient in the diurnal cycle cannot fully explain the buoyancy gradients found in this study. The first issue is that the soil moisture gradient is weakest during the summer months, when the east-west buoyancy gradients are strongest (Figs. 7 and 8, Table 1). The second issue is that the average along-slope gradient in the diurnal temperature cycle is less than half of the average alongslope virtual potential temperature gradient found in the summer months.

The authors hypothesize that the mean negative along-slope buoyancy gradient found in this region may be caused by a nonlinear process that is initiated by the along-slope gradient in diurnal temperature cycle. Consider a scenario where only a north-south gradient in buoyancy exists over the Great Plains (the climatological gradient one would expect at midlatitudes). Due to the gradient in east-west diurnal temperature cycle, an east-west gradient in buoyancy will develop during the daytime. From Eq. (1), one can see that this east-west gradient in buoyancy will cause the geostrophic wind over the western Great Plains to be larger than the geostrophic wind in the eastern plains. Additionally, the slope over the western plains is greater than that in the eastern plains, which will further enhance the east-west gradient in the geostrophic wind. The east-west gradient in wind speed causes differential temperature advection along the slope, which strengthens the east-west buoyancy gradient, due to tilting of the original north-south gradient (Fig. 9). The low-level temperature advection increases buoyancy, which increases the strength of the geostrophic wind creating a positive feedback loop. Over time, this process could result in the buoyancy gradients seen in the composites. This mechanism could also explain why the summer months have stronger, more consistent buoyancy gradients. The poleward retreat of the polar jet stream in the summer months causes quiescent weather over the southern Great Plains, with less frequent cold front passages (Nallapareddy et al. 2011). This allows the buoyancy gradients more time to strengthen via the differential advection mechanism and 
(a)

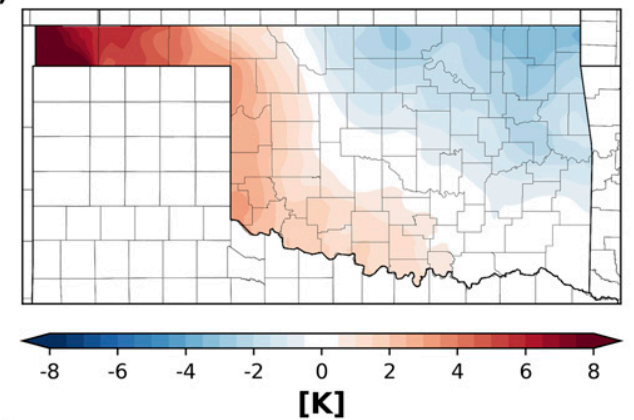

(c)

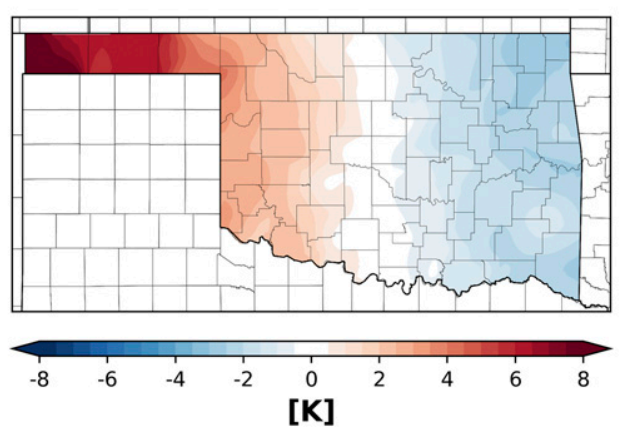

(b)

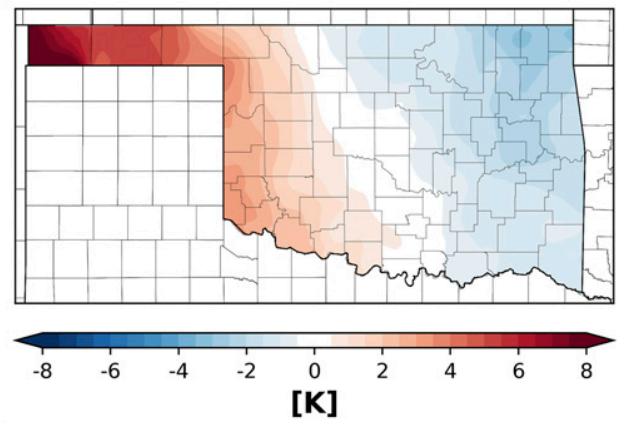

(d)

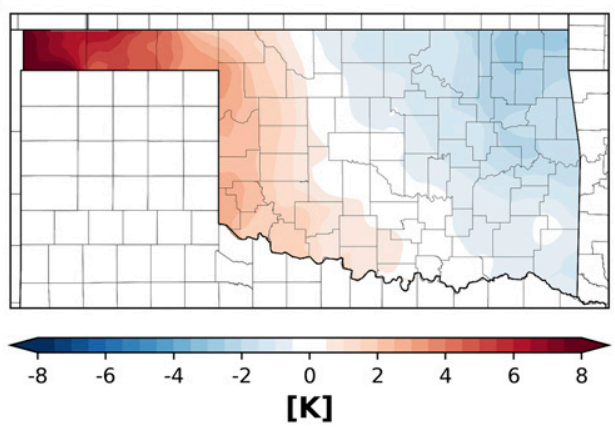

FIG. 8. Composites of spatial anomalies of maximum virtual potential temperature $\left(\hat{\theta}_{v_{\max }}^{s^{\prime}}\right)$ for meteorological (a) winter, (b) spring, (c) summer, and (d) fall.

would cause the gradients to be more persistent in the summer months.

\section{Summary}

Along-slope buoyancy gradients are typically ignored in theoretical studies that consider the forcing for LLJs over the Great Plains, but these gradients can have significant impacts on the strength, frequency, and structure of the LLJs (Gebauer et al. 2018). The present study found that negative along-slope buoyancy gradients are the norm over Oklahoma and become more consistent and frequent in the summer months. The negative along-slope buoyancy gradient is an additional baroclinic forcing that is of the same magnitude as the constant altitude buoyancy gradient underpinning the Holton mechanism and contributes to the large number of southerly LLJs over the region. The cause of the negative buoyancy gradient, however, requires more investigation. An alongslope gradient in the diurnal cycle amplitude helps to create the buoyancy gradients in the afternoon, and the gradient in the diurnal cycle over the Great Plains is closely aligned with the soil moisture gradient in that region. However, the soil moisture gradient and the gradient in the diurnal cycle cannot fully explain the buoyancy gradients, as the diurnal cycle gradient and soil moisture gradient is weaker in the months when the buoyancy gradients are strongest. It is possible that the gradient in diurnal cycle starts a nonlinear process in which differential temperature advection along the slope enhances the along-slope buoyancy gradient. Future work should further explore the cause of the buoyancy gradients over the Great Plains with a more complete analysis of the sensible and latent heat fluxes, and the associated dynamical response to these

TABLE 1. Average gradients of virtual potential temperature, amplitude of the virtual potential temperature diurnal cycle, and fractional water index.

\begin{tabular}{lccc}
\hline \hline & $\begin{array}{c}\text { Gradient of virtual potential } \\
\text { temperature }\left(\mathrm{K} \mathrm{km}^{-1}\right)\end{array}$ & $\begin{array}{c}\text { Gradient of the amplitude of the virtual } \\
\text { potential temperature diurnal } \\
\text { cycle }\left(\mathrm{K} \mathrm{km}^{-1}\right)\end{array}$ & $\begin{array}{c}\text { Gradient of fractional water } \\
\text { index }\left(\mathrm{km}^{-1}\right)\end{array}$ \\
\hline Weason & -0.0099 & -0.0061 & 0.00045 \\
Spring & -0.0109 & -0.0061 & 0.00044 \\
Summer & -0.0116 & -0.0045 & 0.00025 \\
Fall & -0.0095 & -0.0041 & 0.00030 \\
\hline
\end{tabular}




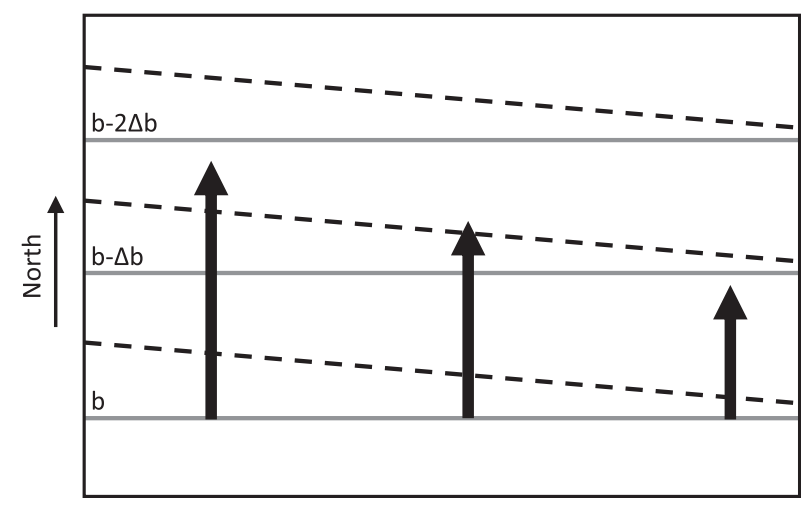

FIG. 9. A conceptual figure illustrating the tilting of a north-south buoyancy gradient into an east-west buoyancy gradient by the geostrophic wind over an eastward facing slope. The solid gray lines represent an initial buoyancy field with buoyancy decreasing to the north. The dashed lines represent the buoyancy field at a later time. This tilting of the gradient is initiated by nonuniform heating of the slope and results in the geostrophic wind field shown (black arrows). This geostrophic wind field acts to further tilt the buoyancy gradient into an east-west orientation creating a positive feedback.

fluxes along the slope. The effect of these negative along-slope buoyancy gradients can also be examined in a numerical model framework where the impact of the temporal and spatial variations of buoyancy gradients on the LLJ can be better represented.

\section{APPENDIX}

\section{Expressing the Geostrophic Wind in the Altimeter Correction System}

Several studies of LLJs have used the altimeter correction system of Bellamy (1945) (Bonner and Paegle 1970; Parish 2016, 2017; Parish and Clark 2017). The Bellamy system contains variables that are defined in relation to an early version of U.S. Standard Atmosphere (Bellamy 1945), where the vertical coordinate is pressure altitude. The pressure altitude for a given point is defined as the altitude at which the pressure at that point occurs in that standard atmosphere. For example, a pressure altitude of $0 \mathrm{~m}$ corresponds to a pressure of $1013.25 \mathrm{hPa}$. At the $0 \mathrm{~m}$ pressure altitude, the standard temperature is $15^{\circ} \mathrm{C}$ and the temperature decreases with height with a $6.5^{\circ} \mathrm{C} \mathrm{km}^{-1}$ lapse rate.

Two variables in Bellamy's system ${ }^{\mathrm{A} 1}$ are defined in relation to the U.S. Standard Atmosphere. The first is the altimeter correction:

\footnotetext{
${ }^{\text {A1 }}$ To avoid a conflict of notation, we have changed some of the notation of that of Bellamy (1945). For example, Bellamy's $z$ and $z_{p}$ are written here as $Z$ and $Z_{p}$.
}

$$
D=Z-Z_{p},
$$

where $Z$ is the height above sea level and $Z_{p}$ is the pressure altitude. The altimeter correction is similar to the perturbation pressure used in the present study. The second variable is the specific virtual temperature anomaly,

$$
S^{*}=\frac{T^{*}-T_{p}}{T_{p}},
$$

where $T_{p}$ is the temperature of the standard atmosphere at pressure $p$, and $T^{*}$ is a virtual temperature defined as

$$
T^{*}=\frac{m_{d}}{m} \frac{g_{p}}{g} T
$$

where $m_{d}$ is the molecular weight of dry air, $m$ is the actual molecular weight of the air, $g_{p}$ is a constant value of gravity equal to $9.8 \mathrm{~m} \mathrm{~s}^{-2}, g$ is the actual gravity, and $T$ is temperature. The specific virtual temperature anomaly is analogous to buoyancy as both represent a thermal perturbation from a reference state.

In this system, Bellamy (1945) shows that the hydrostatic equation is

$$
\frac{\partial D}{\partial Z}=\frac{S^{*}}{1+S^{*}} .
$$

Using (A4), Sangster (1960) expressed the horizontal pressure gradient on an isobaric surface as

$$
\nabla_{p} Z=\nabla_{s} D-S^{*} Z_{p},
$$

where the subscript $\nabla_{p}$ indicates derivatives are evaluated on a pressure surface and the subscript $\nabla_{s}$ indicates derivative are evaluated along sloping terrain. Sangster (1967) then uses (A5) to write the geostrophic wind in the Bellamy system as

$$
V_{g}=\frac{g}{f}\left(\frac{\partial D}{\partial x}-S^{*} \frac{\partial Z_{p}}{\partial x}\right),
$$

where the derivatives are slope following. Applying $Z_{p}=Z-D$ in (A6), one obtains the geostrophic wind equation used by Bonner and Paegle (1970):

$$
V_{g}=\frac{g}{f}\left(1+S^{*}\right) \frac{\partial D}{\partial x}-S^{*} \frac{g}{f} \frac{\partial Z}{\partial x} .
$$

Equation (A7) is similar to (1) in the present study. The second term in (A7) represents the contribution to the geostrophic wind due to the specific virtual temperature anomaly on a sloped surface, which is analogous to the $b \sin \alpha$ term in (1). The first term is a representation of the pressure gradient force, which is analogous to the $\partial \Pi / \partial x$ 
term in (1). Note that the magnitude of $S^{*}$ is on the order of $10^{-2}$ so the $\left(1+S^{*}\right)$ factor of (A7) is very close to 1 .

The relationship between the vertical variation in $\partial D / \partial x$ and horizontal variations in $S^{*}$ can be found by taking the along-slope derivative of (A4). This yields

$$
\frac{\partial}{\partial Z}\left(\frac{\partial D}{\partial x}\right)=\frac{\partial}{\partial x}\left(\frac{S^{*}}{1+S^{*}}\right) .
$$

Equation (A8) indicates that the along-slope gradient in altimeter correction will vary with height if there are along-slope gradients in $S^{*} /\left(1+S^{*}\right)$. This is analogous to the pressure gradient term in (1) varying with height due to along-slope gradients in buoyancy. Bonner and Paegle (1970) found that the gradient in $S^{*} /\left(1+S^{*}\right)$ was persistently negative and the magnitude oscillated in response to the diurnal cycle. Although not immediately clear due to the different equation systems used, the results in Bonner and Paegle (1970) are consistent with the results of the present study.

\section{REFERENCES}

Astling, E. G., J. Paegle, E. Miller, and C. J. O'Brien, 1985: Boundary layer control of nocturnal convection associated with a synoptic scale system. Mon. Wea. Rev., 113, 540-552, https:// doi.org/10.1175/1520-0493(1985)113<0540:BLCONC > 2.0.CO;2.

Bellamy, J. C., 1945: The use of pressure altitude and altimeter corrections in meteorology. J. Meteor., 2, 1-79, https://doi.org/ 10.1175/1520-0469(1945)002<0001:TUOPAA > 2.0.CO;2.

Blackadar, A. K., 1957: Boundary layer wind maxima and their significance for the growth of nocturnal inversions. Bull. Amer. Meteor. Soc., 38, 283-290, https://doi.org/10.1175/15200477-38.5.283.

Bonner, W. D., 1968: Climatology of the low level jet. Mon. Wea. Rev., 96, 833-850, https://doi.org/10.1175/1520-0493(1968) 096<0833:COTLLJ $>2.0$.CO;2.

— , and J. Paegle, 1970: Diurnal variations in boundary layer winds over the south-central United States in the summer. Mon. Wea. Rev., 98, 735-744, https://doi.org/10.1175/15200493(1970)098<0735:DVIBLW >2.3.CO;2.

Brock, F. V., K. C. Crawford, R. L. Elliot, G. W. Cuperus, S. J. Stadler, H. L. Johnson, and M. D. Eilts, 1995: The Oklahoma Mesonet: A technical overview. J. Atmos. Oceanic Technol., 12, 5-19, https://doi.org/10.1175/1520-0426(1995)012<0005: TOMATO $>2.0 . \mathrm{CO} ; 2$.

Carbone, R. E., J. D. Tuttle, D. A. Ahijevych, and S. B. Trier, 2002: Inferences of predictability associated with warm season precipitation episode. J. Atmos. Sci, 59, 2033-2056, https://doi.org/ 10.1175/1520-0469(2002)059<2033:IOPAWW >2.0.CO;2.

Doubler, D., J. Winxler, X. Bian, C. Walters, and S. Zhong, 2015: An NARR-derived climatology of southerly and northerly low-level jets over North America and coastal environs. J. Appl. Meteor. Climatol., 54, 1596-1619, https://doi.org/ 10.1175/JAMC-D-14-0311.1.

Du, Y., and R. Rotunno, 2014: A simple analytical model of the nocturnal low-level jet over the Great Plains of the United States. J. Atmos. Sci., 71, 3674-3683, https://doi.org/10.1175/ JAS-D-14-0060.1.
Fast, J. D., and M. D. McCorcle, 1990: A two-dimensional numerical sensitivity study of the Great Plains low-level jet. Mon. Wea. Rev., 118, 151-163, https://doi.org/10.1175/15200493(1990)118<0151:ATDNSS > 2.0.CO;2.

Gebauer, J. G., A. Shapiro, E. Fedorovich, and P. Klein, 2018: Convection initiation caused by heterogeneous low-level jets over the Great Plains. Mon. Wea. Rev., 146, 2615-2637, https:// doi.org/10.1175/MWR-D-18-0002.1.

Higgins, R., Y. Yao, E. Yarosh, J. Janowiak, and K. Mo, 1997: Influence of the Great Plains low-level jet on summertime precipitation and moisture transport over the central United States. J. Climate, 10, 481-507, https://doi.org/10.1175/15200442(1997)010<0481:IOTGPL>2.0.CO;2.

Holton, J. R., 1967: The diurnal boundary layer wind oscillation above sloping terrain. Tellus, 19, 199-205, https://doi.org/ 10.1111/j.2153-3490.1967.tb01473.x.

Maddox, R. A., 1983: Large-scale meteorological conditions associated with midlatitude, mesoscale convective complexes. Mon. Wea. Rev., 111, 1475-1493, https://doi.org/10.1175/15200493(1983)111<1475:LSMCAW > 2.0.CO;2.

Mahrt, L., 1982: Momentum balance of gravity flows. J. Atmos. Sci., 39, 2701-2711, https://doi.org/10.1175/1520-0469(1982) $039<2701: \mathrm{MBOGF}>2.0 . \mathrm{CO} ; 2$.

McPherson, R. A., and Coauthors, 2007: Statewide monitoring of the mesoscale environment: A technical update on the Oklahoma Mesonet. J. Atmos. Oceanic Technol., 24, 301-321, https://doi.org/10.1175/JTECH1976.1.

Nallapareddy, A., A. Shapiro, and J. J. Gourley, 2011: A climatology of nocturnal warming events associated with coldfrontal passages in Oklahoma. J. Appl. Meteor. Climatol., 50, 2042-2061, https://doi.org/10.1175/JAMC-D-11-020.1.

Parish, T. R., 2016: A comparative study of the 3 June 2015 Great Plains low-level jet. Mon. Wea. Rev., 144, 2963-2979, https:// doi.org/10.1175/MWR-D-16-0071.1.

2017: On the forcing of the summertime Great Plains lowlevel jet. J. Atmos. Sci., 74, 3937-3953, https://doi.org/10.1175/ JAS-D-17-0059.1.

— and L. D. Oolman, 2010: On the role of sloping terrain in the forcing of the Great Plains low-level jet. J. Atmos. Sci., 67, 2690-2699, https://doi.org/10.1175/2010JAS3368.1.

— and R. D. Clark, 2017: On the initiation of the 20 June 2015 Great Plains low-level jet. J. Appl. Meteor. Climatol., 56, 18831895, https://doi.org/10.1175/JAMC-D-16-0187.1.

—_, A. R. Rodi, and R. D. Clark, 1988: A case study of the summertime Great Plains low-level jet. Mon. Wea. Rev., 116, 94-105, https://doi.org/10.1175/1520-0493(1988) $116<0094$ :ACSOTS $>2.0$. CO;2.

Pitchford, K. L., and J. London, 1962: The low-level jet as related to nocturnal thunderstorms over Midwest United States. J. Appl. Meteor., 1, 43-47, https://doi.org/10.1175/1520-0450(1962) 001<0043:TLLJAR > 2.0.CO;2.

Rasmusson, E. M., 1967: Atmospheric water vapor transport and the water balance of North America. Part I: Characteristics of the water vapor flux field. Mon. Wea. Rev., 95, 403-426, https:// doi.org/10.1175/1520-0493(1967)095<0403:AWVTAT>2.3.CO;2.

Revathy, K., S. R. Prabhakaran Nair, and B. V. Krishna Murthy, 1996: Deduction of temperature profile from MST radar observations of vertical wind. Geophys. Res. Lett., 23, 285-288, https://doi.org/10.1029/96GL00086.

Rife, D. L., J. O. Pinto, A. J. Monaghan, and C. A. Davis, 2010: Global distribution and characteristic of diurnally varying lowlevel jets. J. Climate, 23, 5041-5063, https://doi.org/10.1175/ 2010JCLI3514.1. 
Sangster, W. E., 1960: A method of representing the horizontal pressure force without reduction of station pressures to sea level. J. Meteor., 17, 166-176, https://doi.org/10.1175/15200469(1960)017<0166:AMORTH>2.0.CO;2.

Sangster, W. W., 1967: Diurnal surface geostrophic wind variations over the Great Plains. Proc. Fifth Conf. on Severe Local Storms, St. Louis, MO, Amer. Meteor. Soc., 146-153.

Schmid, P., and D. Niyogi, 2012: A method for estimating planetary boundary layer heights and its application over the ARM Southern Great Plains site. J. Atmos. Oceanic Technol., 29, 316-322, https://doi.org/10.1175/JTECH-D11-00118.1.

Schneider, J. M., D. K. Fisher, R. L. Elliott, G. O. Brown, and C. P. Bahrmann, 2003: Spatiotemporal variations in soil water: First results from the ARM SGP CART network. J. Hydrometeor., 4, 106-120, https://doi.org/10.1175/1525-7541(2003)004<0106: SVISWF $>2.0 . \mathrm{CO} ; 2$.

Shapiro, A., E. Fedorovich, and S. Rahimi, 2016: A unified theory for the Great Plains nocturnal low-level jet. J. Atmos. Sci., 73, 3037-3057, https://doi.org/10.1175/JAS-D-15-0307.1.

, ——, and J. G. Gebauer, 2018: Mesoscale ascent in nocturnal low-level jets. J. Atmos. Sci., 75, 1403-1427, https://doi.org/ 10.1175/JAS-D-17-0279.1.

Song, J., K. Liao, R. L. Coulter, and B. M. Lesht, 2005: Climatology of the low-level jet at the southern Great Plains Atmospheric Boundary Layer Experiments site. J. Appl. Meteor., 44, 15931606, https://doi.org/10.1175/JAM2294.1.

Trier, S. B., C. A. Davis, D. A. Ahijevych, M. L. Weisman, and G. H. Bryan, 2006: Mechanisms supporting long-lived episodes of propagating nocturnal convection within a 7-day
WRF Model simulation. J. Atmos. Sci., 63, 2437-2461, https:// doi.org/10.1175/JAS3768.1.

_, - and R. E. Carbone, 2014: Mechanisms governing the persistence and diurnal cycle of a heavy rainfall corridor. J. Atmos. Sci., 71, 4102-4126, https://doi.org/10.1175/JAS-D-14-0134.1.

Tsuda, T., T. E. VanZandt, M. Mizumoto, S. Kato, and S. Fukao, 1991: Spectral analysis of temperature and Brunt-Vaisala frequency fluctuations observed by radiosondes. J. Geophys. Res., 96, 17 265-17 278, https://doi.org/10.1029/91JD01944.

Tuttle, J. D., and C. A. Davis, 2006: Corridors of warm season precipitation in the central United States. Mon. Wea. Rev., 134, 2297-2317, https://doi.org/10.1175/MWR3188.1.

Walters, C. K., and J. A. Winkler, 2001: Airflow configurations of warm season southerly low-level wind maxima in the Great Plains. Part I: Spatial and temporal relationship to convection. Wea. Forecasting, 16, 513-530, https://doi.org/10.1175/15200434(2001)016<0513:ACOWSS > 2.0.CO;2.

_ - — - R. P. Shadbolt, J. van Ravensway, and G. D. Bierly, 2008: A long-term climatology of southerly and northerly lowlevel jets for the central United States. Ann. Assoc. Amer. Geogr., 98, 521-552, https://doi.org/10.1080/00045600802046387.

Whiteman, C. D., X. Bian, and S. Zhong, 1997: Low-level jet climatology from enhanced rawinsonde observations at a site in the southern Great Plains. J. Appl. Meteor., 36, 1363-1376, https:// doi.org/10.1175/1520-0450(1997)036<1363:LLJCFE > 2.0.CO;2.

Zhong, S., J. D. Fast, and X. Bian, 1996: A case study of the Great Plains low-level jet using wind profiler network data and a high-resolution mesoscale model. Mon. Wea. Rev., 124, 785-806, https://doi.org/10.1175/1520-0493(1996) $124<0785$ :ACSOTG $>2.0$.CO;2. 